\title{
SÍNTESE DE BIODIESEL A PARTIR DE RESÍDUOS GORDUROSOS DE FRITURA UTILIZANDO COMO FERRAMENTA PLANEJAMENTO FATORIAL
}

\author{
Cleiton Barcot Tintor ${ }^{1}$, Daniela Battaglia Hirata ${ }^{2}$ e Ernandes Benedito \\ Pereira $^{3}$
}

\begin{abstract}
Resumo: O objetivo deste trabalho foi a produção de biodiesel via rota enzimática, utilizando resíduo gorduroso de fritura como substrato e o planejamento fatorial como ferramenta de análise. O planejamento fatorial foi empregado para avaliar os parâmetros da reação de transesterificação, quanto à razão molar óleo:etanol (1:3; 1:4,7; 1:9; 1:13,3 e 1:15) e temperatura (30, 34, 45, 56 e $\left.60^{\circ} \mathrm{C}\right)$. A reação foi conduzida em shaker, usando $20 \mathrm{~g}$ do meio reaciona e $2 \mathrm{~g}$ do derivado imobilizado de lipase durante $15 \mathrm{~h}$. Os diferentes ensaios foram avaliados por cromatografia gasosa (verificação do teor de ésteres de etila) e viscosímetro, mostrando uma produção de $67,9 \%$ de ésteres de etila para a razão molar óleo:etanol de $1: 4,7$ e $34^{\circ} \mathrm{C}$ de temperatura; e uma viscosidade de 3,82 cP para a razão molar óleo:etanol de $1: 3$ e $45^{\circ} \mathrm{C}$ de temperatura, sendo estes os melhores resultados, indicando que a variável que interferiu significativamente no rendimento da reação foi a temperatura.
\end{abstract}

Palavras-chave: Resíduo gorduroso de fritura. Planejamento fatorial. Biodiesel.

\section{Introdução}

A questão energética sempre foi de suma importância para a história da humanidade. Todos os tipos de bem de consumo doméstico, os carros e as vias de rodagem, as roupas e alimentos, requerem energia para serem produzidos e embalados, distribuídos às lojas ou em domicílio, operados e depois descartados (SAWIN, 2004).

As fontes energéticas são limitadas e o seu eminente esgotamento impulsiona a visão de uma fonte alternativa de energia. Assim sendo, o biodiesel apresenta potencial para a substituição de diversos derivados do petróleo. Conforme a resolução $n^{\circ} 45$ da Agência Nacional de Petróleo, Gás Natural e Biocombustíveis (ANP), biodiesel é um biocombustível derivado de uma biomassa renovável para uso em motores a combustão interna com ignição por compressão ou, conforme regulamentos, para geração de outro tipo de energia, que possa substituir parcial ou totalmente combustíveis de origem fóssil (BRASIL, 2014).

O uso do biodiesel pode ser justificado devido ao fato de: (1) ser uma alternativa à dependência dos derivados de petróleo; (2) ser um componente obrigatório na composição do óleo diesel nacional; (3) criar um novo mercado para as oleaginosas, favorecendo os pequenos produtores; (4) gerar a perspectiva de redução da emissão de poluentes ao meio (LEIRAS, 2006).

O biodiesel é obtido por transesterificação etílica dos óleos e gorduras de várias origens. Portanto, teoricamente, qualquer forma de óleos e gorduras proveniente de animais, plantas ou microrganismos podem ser usados como matéria-prima para produção de biodiesel (TIANWEl et al., 2010). Sendo assim, ressalta-se que o uso destas matérias em diferentes processos de esterificação e transesterificação, com emprego de diferentes rotas catalíticas, são reações capazes de produzir biodiesel (VASCONCELOS, 2011).

Várias pesquisas relacionadas à transesterificação alcoólica de óleos e gorduras envolvem o uso de catalisadores heterogêneos como, por exemplo, zeólitas básicas, óxidos e carbonatos de metais alcalinos terrosos e enzimas, em particular lipases (PINTO et al., 2005).

Os catalisadores enzimáticos oferecem diferentes possibilidades frente aos

${ }^{1}$ E-mail: ctintor@gmail.com

${ }^{2}$ E-mail: daniela.hirata@unifal-mg.edu.br 


\section{REA - Revista de estudos ambientais (Online) v.17, n. 2, p.51-59, jul./dez. 2015}

catalisadores ácidos e básicos, como a menor sensibilidade a presença de água (não formam sabões), recuperação do catalisador e maior facilidade na separação do biodiesel, além de ser uma opção mais atrativa ambientalmente. A enzima imobilizada em um suporte é sempre mais ativa que a livre em condições reacionais comparáveis, uma vez que o sistema heterogêneo disponibiliza os sítios ativos das enzimas quando confinadas nos poros do sólido, enquanto que em sistema homogêneo ocorre a formação de agregados, confinando os sítios no interior destes (CASTRO et al., 2004; HA et al., 2007). Há que se considerar ainda que, o uso de enzimas imobilizadas reduz o impacto ambiental, quando comparado com o uso dos demais catalisadores, visto que a recuperação do catalisador é simplificada, com a mínima produção de resíduos de descarte no processo. Como inconveniente, há $o$ elevado custo $e$ as dificuldades referentes ao controle do processo que ainda inviabilizam seu uso (VILLENEUVE et al., 2000; WANG et al., 2008).

Para a produção de biodiesel, Souza (2003, 2010) desenvolveu estudos que tiveram como matéria prima básica o resíduo gorduroso, seja ele proveniente de caixas de gorduras ou de frituras.

A enzima utilizada foi a Lipase AK, comercialmente distribuída pela empresa Sigma Aldrich Co. (USA) na forma de pó liofilizado, de origem microbiana extraída do fungo Pseudomonas fluorescens.
De forma geral, este trabalho tem como objetivo produzir ésteres de ácidos graxos (biodiesel) por via enzimática utilizando a rota etílica (etanol), a partir das matérias-primas gordurosas residuais, de baixo custo, oriundas de bares, restaurantes e lanchonetes comerciais, as quais são normalmente, depositadas em aterros sanitários ou em estações de tratamento de efluentes.

Para a avaliação do grau de significância, utilizou-se um planejamento fatorial, o qual verificou a interação das variáveis temperatura, razão molar óleoetanol e concentração do substrato e da enzima, no interesse de otimizar a reação de transesterificação com uso de via enzimática.

\section{Materiais e métodos}

\subsection{Materiais}

O substrato utilizado para a reação de transesterificação foi o resíduo gorduroso de fritura caracterizada conforme mostrado na Tabela 1, obtido no restaurante universitário da UNIFAL-MG, campus sede, Alfenas/MG, numa única amostra com volume de dois litros.

O suporte inerte Polihidroxibutirato (PHB) utilizado também é comercializado na forma de pó, pela empresa Sigma Aldrich Co. (USA).

Tabela 1 - Caracterização da matéria prima em comparação a valores de referência ou da literatura

\begin{tabular}{|c|c|c|c|c|}
\hline Parâmetro avaliado & Valor obtido & Desvio padrão & $\begin{array}{l}\text { Valores de } \\
\text { referência }\end{array}$ & $\begin{array}{l}\text { Valores da } \\
\text { literatura }\end{array}$ \\
\hline $\begin{array}{l}\text { Teor de acidos graxos livres } \\
\text { (mg/g) }\end{array}$ & 0,79 & 0,25 & $<0,6^{a}$ & $0,13-4,57^{b}$ \\
\hline $\begin{array}{l}\text { Índice de acidez total } \\
(\mathrm{mg} / \mathrm{g})\end{array}$ & 0,39 & 0,01 & $<0,5^{c}$ & $0,14-5,77^{d}$ \\
\hline $\begin{array}{l}\text { Índice de iodo } \\
(\mathrm{g} / 100 \mathrm{~g})\end{array}$ & 26,83 & 0,58 & $120-143^{e}$ & $119,35-121,82^{\dagger}$ \\
\hline $\begin{array}{l}\text { Índice de saponificação } \\
(\mathrm{mg} / \mathrm{g})\end{array}$ & 106,88 & --- & $189-195^{\mathrm{e}}$ & --- \\
\hline $\begin{array}{l}\text { Índice de peróxido } \\
(\mathrm{meq} / \mathrm{kg})\end{array}$ & 8,79 & 0,53 & $<10^{\mathrm{e}}$ & --- \\
\hline Viscosidade $(\mathrm{cP})$ & 23,49 & & --- & --- \\
\hline Teor de umidade (\%) & 0,10 & 0,01 & --- & $0,11^{\mathrm{b}}$ \\
\hline Densidade $\left(\mathrm{g} / \mathrm{dm}^{3}\right)$ & 0,92 & --- & --- & -- \\
\hline
\end{tabular}


v.17, n. 2, p.51-59, jul./dez. 2015

\subsection{Procedimento experimental}

\subsubsection{Imobilização da lipase por adsorção física}

O modo de preparo da imobilização da lipase AK foi selecionado com base nos resultados satisfatórios obtidos na síntese de biodiesel a partir do óleo de café e óleo de soja, conforme pesquisado por Scamilhe et al. (2012).

Cada grama de suporte foi ativado em $10 \mathrm{~mL}$ de etanol absoluto e lavado com $250 \mathrm{~mL}$ de água destilada. Em seguida foi adicionado a lipase $\mathrm{AK}$, previamente pesada para um carregamento de $30 \mathrm{mg}$ de enzima para cada grama de PHB. Utilizou-se um tubo do tipo falcon de $50 \mathrm{~mL}$ e foi adicionado $20 \mathrm{~mL}$ de solução tampão fosfato $0,01 \mathrm{M}$ juntamente a enzima. Após a homogeneização da solução, adicionou-se 1 grama de PHB ativado, que permaneceu em agitação por 12 horas, a $125 \mathrm{rpm}$, em temperatura ambiente $\left(25 \pm 5^{\circ} \mathrm{C}\right)$, num agitador orbital a seco.

Após esta etapa, a lipase imobilizada em PHB foi filtrada com bomba a vácuo e lavada com $50 \mathrm{~mL}$ de água destilada/g.

\subsubsection{Reação de transesterificação enzimática do resíduo gorduroso de fritura e etanol}

As reações foram realizadas em frascos de $250 \mathrm{~mL}$, hermeticamente fechados e incubados em um shaker rotativo, com banho-maria para controle de temperatura, a $200 \mathrm{rpm}$. As quantidades de substrato de reação eram variáveis, de acordo com as combinações molares propostas (Tabela 2), a massa reacional fixada em $20 \mathrm{~g}$ e a concentração de derivado imobilizado foi estabelecida como sendo $10 \%$ em relação à massa total dos reagentes. Após $15 \mathrm{~h}$ de reação, a amostra foi retirada e em seguida foi feita a purificação do biodiesel.

Para a purificação, inicialmente foi retirado 0 derivado imobilizado. Considerando a densidade do PHB, o uso de centrífuga laboratorial para tubo falcon de 15 $\mathrm{mL}$ foi funcional. Após a rotação, verificouse que a amostra separava-se em duas fases, na porção mais baixa do tubo estava o derivado imobilizado e na porção superior estava a amostra de interesse, a qual continha o biodiesel em mistura com glicerol, o etanol não reagido e a água resultante da reação.

Após coleta da fase superior, foi feita a lavagem da amostra. Nessa etapa, utilizouse água quente, $\left(65 \pm 5^{\circ} \mathrm{C}\right)$, emulsificando os subprodutos da reação (glicerina) e, por meio de centrifugação foi possível retê-los na fase inferior. A lavagem foi repetida por três vezes.

$\mathrm{Na}$ etapa final (a purificação), a amostra foi submetida a evaporador rotativo a $75^{\circ} \mathrm{C}$ e rotação de $100 \mathrm{rpm}$ e, em seguida, adicionou-se sal sulfato de sódio anidro, numa proporção de $1 / 3$ do total do volume amostrado e aguardou-se $24 \mathrm{~h}$.

Para a separação do sal, foi realizada uma nova centrifugação. A cada etapa de centrifugação, utilizou-se uma rotação de $2000 \mathrm{rpm}$, por período de 5 minutos.

\subsubsection{Delineamento experimental}

Com a finalidade de encontrar a melhor combinação dos diferentes fatores que afetam a reação, foi realizado um delineamento composto central rotacional (DCCR), ou seja, um planejamento $2^{2}$ incluindo 4 ensaios nas condições axiais e 3 repetições no ponto central, totalizando 11 ensaios (Tabela 2). As variáveis independentes avaliadas foram temperatura $\left(X_{1}\right)$ e razão molar entre resíduo gorduroso de fritura e etanol $\left(X_{2}\right)$ tendo como repostas a formação do éster etílico e a viscosidade. Os níveis das variáveis foram escolhidos baseados na importância dos mesmos para o processo de transesterificação. O tempo de reação foi fixado em 15 horas com agitação constante de $200 \mathrm{rpm}$.

Foi efetuado um planejamento fatorial fracionário, sendo que este fatorial possui uma característica importante: os seus contrastes não misturam os efeitos principais com interações de dois fatores, e sim com interação de três fatores, que em princípio devem ser menos significativas e por isso, desprezíveis (BOX; HUNTER; WUNTER, 1978)

O software Statistic versão 7 (STAT SOFT INC., 2004) foi usado para análise e construção das superfícies de respostas. 


\section{REA - Revista de estudos ambientais (Online) \\ v.17, n. 2, p.51-59, jul./dez. 2015}

Tabela 2 - Valores utilizados no delineamento composto central rotacional (DCCR) para a reação de transesterificação enzimática utilizando a lipase de Pseudomonas fluorescens (lipase AK)

\begin{tabular}{cccccc}
\hline Variáveis & \multicolumn{7}{c}{ Níveis } \\
\cline { 2 - 6 } & $\mathbf{- 1 , 4 1}$ & $\mathbf{- 1}$ & $\mathbf{0}$ & $\mathbf{+ 1}$ & $\mathbf{+ 1 , 4 1}$ \\
\hline Razão molar $\left(\mathrm{X}_{1}\right)$ & $1: 3$ & $1: 4,7$ & $1: 9$ & $1: 13,3$ & $1: 15$ \\
Temperatura $\left({ }^{\circ} \mathrm{C}\right)\left(\mathrm{X}_{2}\right)$ & 30 & 34 & 45 & 56 & 60 \\
\hline
\end{tabular}

Fonte: Os Autores (2015)

\subsubsection{Determinação da viscosidade}

A viscosidade absoluta foi medida em viscosímetro Brookfield Modelo LVDVII (Brookfield Viscometers Ltd., Inglaterra) empregando o cone CP 42 (faixa de viscosidade de 0,3 a $6000 \mathrm{cP}$ ). As medidas foram feitas no resíduo gorduroso de fritura bruto (não reagido) e no biodiesel purificado.

\subsubsection{Determinação do teor de esteres formados e rendimento da reação}

Para a determinação do teor de monoésteres de ácidos graxos, foi utilizado cromatografia de fase gasosa, de acordo com metodologia desenvolvida por Urioste et al. (2008). O rendimento das reações de síntese de biodiesel foi definido como o valor que expressa a massa total obtida de ésteres de etila (Mt) em relação à massa teórica esperada de ésteres de etila (Me). Me foi determinado a partir da massa de ácidos graxos presente na massa inicial do extrato de resíduo gorduroso de fritura preparado $\left(\mathrm{M}_{0}\right)$, da massa molecular correspondente a cada ácido (MMa) e do éster correspondente (MMe).

\section{Resultados e discussão}

$\mathrm{Na}$ Tabela 3 são apresentados o rendimento em éster etílico e a viscosidade para as diversas condições testadas num período de $15 \mathrm{~h}$ de reação. Inicialmente, o resíduo gorduroso de fritura bruto apresentou um valor médio de viscosidade $23,49 \mathrm{cP}$ (Tabela 1).

Tabela 3 - Matriz padrão para o experimento de síntese de biodiesel pela lipase imobilizada em Polihidroxibutirato(PHB) *

\begin{tabular}{ccccc}
\hline Ensaios & Razão molar & Temperatura $\left({ }^{\circ} \mathbf{C}\right.$ ) & Viscosidade (cP) & Ésteres (\%) \\
\hline $\mathbf{1}$ & $1: 4,7$ & 34 & 6,83 & 67,9 \\
$\mathbf{2}$ & $1: 13,3$ & 34 & 4,71 & 61,0 \\
$\mathbf{3}$ & $1: 4,7$ & 56 & 8,09 & 53,9 \\
$\mathbf{4}$ & $1: 13,3$ & 56 & 8,29 & 55,8 \\
$\mathbf{5}$ & $1: 3$ & 45 & 3,82 & 67,1 \\
$\mathbf{6}$ & $1: 15$ & 45 & 8,44 & 57,0 \\
$\mathbf{7}$ & $1: 9$ & 30 & 7,47 & 61,8 \\
$\mathbf{8}$ & $1: 9$ & 60 & 10,85 & 47,6 \\
$\mathbf{9}$ & $1: 9$ & 45 & 7,08 & 63,9 \\
$\mathbf{1 0}$ & $1: 9$ & 45 & 6,53 & 63,5 \\
$\mathbf{1 1}$ & $1: 9$ & 45 & 6,53 & 59,3
\end{tabular}

${ }^{*}$ Condições: Volume de substrato $=20 \mathrm{~mL} ; 15$ horas de reação e Lipase imobilizada $=30 \mathrm{mg} / \mathrm{g}$ de suporte seco.

Fonte: Autores (2015) 
Os resultados obtidos indicaram que a lipase AK imobilizada foi capaz de converter os triglicerídeos presentes no resíduo gorduroso de fritura em todas as condições avaliadas pelo planejamento. As porcentagens de ésteres etílicos formados variaram de 47 a $68 \%$ após 15 h de reação. A maior porcentagem de ésteres $(67,9 \%)$ foi observada para a reação realizada nas condições do ensaio 1 (razão molar óleo:etanol de 1:4,7 e temperatura de $34^{\circ} \mathrm{C}$ ). Pode-se afirmar que para esta condição, a razão molar no meio reacional aliado à temperatura de $34^{\circ} \mathrm{C}$ favoreceu a maior liberação de ésteres. Uma possível explicação para este resultado é de que na temperatura de $34^{\circ} \mathrm{C}$ a enzima imobilizada em PHB é mais ativa do que nas demais temperaturas analisadas. Verificou-se que no ensaio 8, no qual foi utilizado a maior temperatura $\left(60^{\circ} \mathrm{C}\right)$, foi obtido o menor valor de porcentagem de ésteres $\left(47,6^{\circ} \mathrm{C}\right)$. A enzima também apresentou uma boa resistência ao etanol, isto pode ser observado nos ensaios do ponto central, no qual a razão molar era de 1:9, sendo observados bons resultados de porcentagem de ésteres $(63,9 ; 63,5 ; 59,3 \%)$. Observou-se que para a condição do nível $+1,41$ (ensaio $6)$, no qual foi utilizada a maior razão molar $(1: 15)$ a porcentagem de ésteres obtida foi de $57 \%$, comprovando dessa forma, que a influência da temperatura foi superior a da razão molar para as condições analisadas pelo planejamento fatorial.

O segundo maior valor de porcentagem de ésteres foi observado para o ensaio 5, no qual foi utilizado a razão estequiométrica entre o resíduo gorduroso de fritura e o álcool, mas o ensaio ocorreu na temperatura de máxima atividade da enzima imobilizada $\left(45^{\circ} \mathrm{C}\right)$, reafirmando, mais uma vez, que a temperatura foi a variável que apresentou maior influência para as os ensaios realizados, provavelmente devido a sua interferência direta na atividade dos sítios enzimáticos.

A viscosidade variou de 10,85 a 3,82 cP. Ressalta-se que a viscosidade do resíduo gorduroso de fritura na forma bruta era de 23,49 cP indicando que houve formação de biodiesel em todos os ensaios analisados.

No planejamento foram considerados estatisticamente significativos os termos em que $p<0,05$, ou seja, a $5 \%$ de significância. $\mathrm{Na}$ Tabela 4 é possível observar que o termo linear da razão molar e os termos linear e quadrático da temperatura foram estatisticamente significativos. Desta forma os termos não estatisticamente significativos foram retirados do modelo e adicionados aos erros, gerando a Tabela 5 .

A ANOVA (Tabela 6) para os termos estaticamente significativos apresentou uma boa porcentagem de variação $\left(R^{2}=87 \%\right)$ explicada pelo modelo. $\mathrm{O}$ valor obtido de 15,76 para o Fcalc foi significativo, sendo possível a construção da superfície de resposta para a análise dos resultados por superfície (Figura 1). O modelo, somente para os parâmetros significativos, com as variáveis codificadas para a porcentagem de ésteres formados em função da razão molar e da temperatura para a faixa estudada está representado pela Equação 1.

Tabela 4 - Coeficientes de regressão para a porcentagem de conversão de ésteres

\begin{tabular}{lcccccc}
\hline & $\begin{array}{c}\text { Coef. de } \\
\text { Regressão }\end{array}$ & $\begin{array}{c}\text { Erro } \\
\text { Padrão }\end{array}$ & $\mathbf{t}(\mathbf{5})$ & p-valor & $\begin{array}{c}\text { Lim. de } \\
\text { Conf. } \\
-95 \%\end{array}$ & $\begin{array}{c}\text { Lim. de } \\
\text { Conf. } \\
\mathbf{9 5 \%}\end{array}$ \\
\hline Média & 62,23 & 1,35 & 46,29 & 0,000000 & 58,78 & 65,68 \\
$\left(\mathrm{x}_{1}\right)$ razão molar(L) & $-2,41$ & 0,82 & $-2,93$ & 0,032707 & $-4,53$ & $-0,29$ \\
Razão molar(Q) & 0,23 & 0,98 & 0,23 & 0,825914 & $-2,29$ & 2,75 \\
$\left(\mathrm{X}_{2}\right)$ temperatura(L) & $-4,91$ & 0,82 & $-5,97$ & 0,001896 & $-7,03$ & $-2,80$ \\
Temperatura (Q) & $-3,45$ & 0,98 & $-3,52$ & 0,016940 & $-5,97$ & $-0,93$ \\
$1(\mathrm{~L})$ por 2 (L) & 2,20 & 1,16 & 1,89 & 0,117409 & $-0,79$ & 5,19 \\
\hline
\end{tabular}

Fonte: Autores (2015) 
v.17, n. 2, p.51-59, jul./dez. 2015

$\%$ de Ésteres $=62,44-2,41 x_{1}-4,91 x_{2}-3,51 x_{2}{ }^{2}$

Tabela 5 - Coeficientes de regressão estatisticamente significativos para a porcentagem de conversão de ésteres

\begin{tabular}{lcccccc}
\hline & $\begin{array}{c}\text { Coef. de } \\
\text { Regressão }\end{array}$ & $\begin{array}{c}\text { Erro } \\
\text { Padrão }\end{array}$ & $\mathbf{t}(\mathbf{5})$ & p-valor & $\begin{array}{c}\text { Lim. de } \\
\text { Conf. } \\
\mathbf{- 9 5 \%}\end{array}$ & $\begin{array}{c}\text { Lim.de } \\
\text { Conf. } \\
\mathbf{9 5 \%}\end{array}$ \\
\hline Média & 62,44 & 1,09 & 57,52 & 0,000000 & 59,88 & 65,01 \\
$\left(X_{1}\right)$ razão molar (L) & $-2,41$ & 0,91 & $-2,64$ & 0,033526 & $-4,57$ & $-0,25$ \\
$\left(X_{2}\right)$ temperatura (L) & $-4,91$ & 0,91 & $-5,37$ & 0,001038 & $-7,07$ & $-2,75$ \\
Temperatura (Q) & $-3,51$ & 1,04 & $-3,38$ & 0,011741 & $-5,97$ & $-1,06$ \\
\hline
\end{tabular}

Fonte: Autores (2015)

Tabela 6 - Análise de variância (ANOVA) para a porcentagem de ésteres em função da razão molar e da temperatura

\begin{tabular}{lccccc}
\hline Fonte de variação & $\begin{array}{c}\text { Soma dos } \\
\text { Quadrados }\end{array}$ & $\begin{array}{c}\text { Graus de } \\
\text { liberdade }\end{array}$ & $\begin{array}{c}\text { Quadrado } \\
\text { Médio }\end{array}$ & Fcalc & p-valor \\
\hline Regressão & 315,7291 & 3 & 105,24 & 15,76 & 0,001702 \\
Resíduos & 46,76 & 7 & 6,68 & & \\
Falta de Ajuste & 33,77 & & & & \\
Erro Puro & 12,99 & 10 & & & \\
Total & 362,4891 & 10 & & & \\
\hline
\end{tabular}

\% variação explicada $\left(R^{2}\right)=87,1 \% ; F_{3 ; 7 ; 0,05}=4,347$ Fonte: Autores (2015)

Observando a superfície de resposta e a curva de contorno gerada pelo modelo é possivel afirmar que é esperada uma elevada conversão de ésteres para toda a faixa de razão molar estudada e para valores inferiores ao nível $+1\left(56^{\circ} \mathrm{C}\right)$ da temperatura.

Com relação à temperatura, os dados obtidos neste planejamento confirmaram os resultados referentes à influência da temperatura na atividade da lipase imobilizada. Desta forma, o progresso da transesterificação catalisada por lipase imobilizada em PHB dependeu principalmente da temperatura, porém também houve influência da razão molar, sendo esta em menor escala.

Esses resultados sugerem que a preparação de lipase imobilizada não perde sua atividade frente a elevadas concentrações de álcool etílico não sofrendo uma influência tão marcante da razão molar entre os materiais de partida na formação do produto (ensaios 3,4 e 6 ) (CASTRO et al., 2004), uma vez que somente para os níveis mais elevados de razão molar $(+1,41)$ é que a reação foi levemente desfavorecida.

Em relação à viscosidade, não foram observadas variáveis significativas a $5 \%$ de significância. Porém, a 10\% de significância o termo linear da temperatura foi significativo (Tabela 7).

O valor de $R^{2}$ ficou em $71,82 \%$ quando foram utilizadas todas as variáveis a $10 \%$ de significância, o que significa que o modelo gerado não se ajustou bem aos dados experimentais e que não é aconselhável a construção da superfície de resposta para a análise dos dados experimentais. 


\section{REA - Revista de estudos ambientais (Online) v.17, n. 2, p.51-59, jul./dez. 2015}

Figura 1- Superfície de resposta (A) e curva de contorno (B) para \% de ésteres em função da razão molar $(\mathrm{m} / \mathrm{m})$ e da temperatura $\left({ }^{\circ} \mathrm{C}\right)$
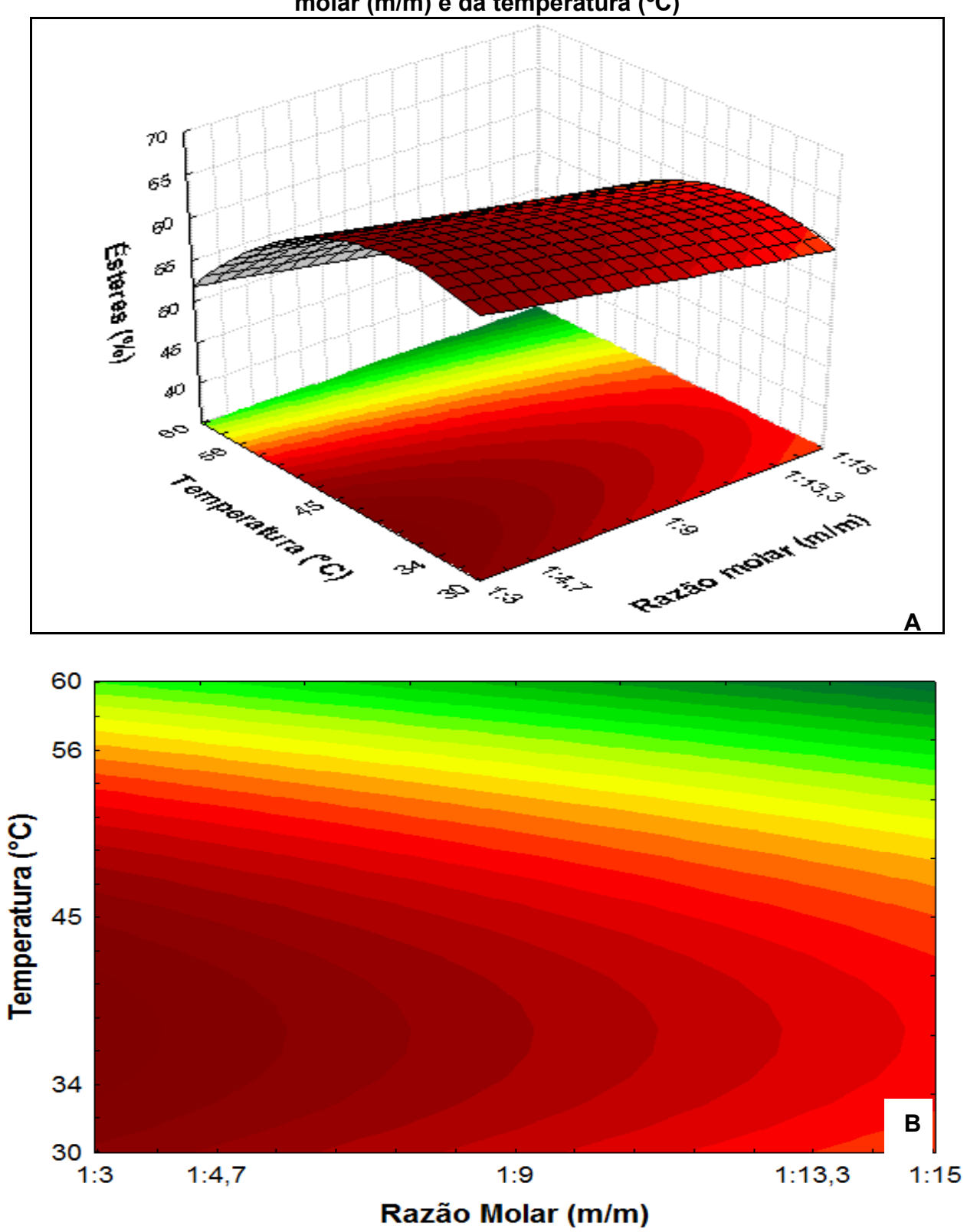

Fonte: Autores (2015)

Tabela 7 - Coeficientes de regressão tendo a viscosidade como resposta

\begin{tabular}{lcccccc}
\hline & $\begin{array}{c}\text { Coef. de } \\
\text { Regressão }\end{array}$ & $\begin{array}{c}\text { Erro } \\
\text { Padrão }\end{array}$ & $\mathbf{t}(\mathbf{5})$ & p-valor & $\begin{array}{c}\text { Lim. de } \\
\text { Conf. } \\
\mathbf{9 5 \%}\end{array}$ & $\begin{array}{c}\text { Lim.de } \\
\text { Conf. } \\
\mathbf{9 5 \%}\end{array}$ \\
\hline Média & 6,71 & 0,82 & 8,2 & 0,000435 & 5,07 & 8,36 \\
$\left(X_{1}\right)$ razão molar (L) & 0,58 & 0,50 & 1,15 & 0,301301 & $-0,43$ & 1,59 \\
razão molar(Q) & $-0,46$ & 0,60 & $-0,77$ & 0,476791 & $-1,70$ & 0,74 \\
$\left(X_{2}\right)$ temperatura (L) & 1,20 & 0,50 & 2,40 & 0,061419 & $-0,19$ & 2,21 \\
temperatura (Q) & 1,06 & 0,60 & 1,77 & 0,136153 & $-0,14$ & 2,26 \\
$1(\mathrm{~L})$ por 2 (L) & 0,59 & 0,71 & 0,82 & 0,449816 & $-0,85$ & 2,01 \\
\hline
\end{tabular}

Fonte: Autores (2015) 
Apesar de não ter sido feita a análise de superfície, pôde-se obter bons valores de viscosidade quando comparado à viscosidade do resíduo gorduroso de fritura bruto. Além disso, esses ensaios foram importantes para avaliar a interação entre as variáveis, visto que tais interações não poderiam ser previstas de outra maneira. Sendo assim, pôde-se concluir que para a viscosidade a temperatura também foi a

\section{Conclusões}

No planejamento experimental da reação de transesterificação na produção de biodiesel por via enzimática, foi verificada a influência das variáveis temperatura e razão molar óleo-etanol que, num período de $15 \mathrm{~h}$, atingiu $68 \%$ de conversão em ésteres etílicos e uma redução na viscosidade de $83,73 \%$. variável mais importante, pois foi para o ensaio no qual foi utilizada a maior temperatura (ensaio $8,60^{\circ} \mathrm{C}$ ) em que foi observado o maior valor de viscosidade $(10,85 \mathrm{cP})$. Pode-se afirmar que a menor conversão em ésteres levou a um maior valor de viscosidade da amostra, e que isto foi consequência de uma menor atividade da enzima imobilizada frente à temperatura de $60^{\circ} \mathrm{C}$ durante a reação de transesterificação.

O conjunto de dados obtidos sugere que a formação de ésteres etílicos a partir do resíduo gorduroso de fritura é viável para o catalisador testado. O biocatalisador atuou de forma eficiente convertendo os ácidos graxos presentes na matéria-prima lipídica nos ésteres etílicos correspondentes. Entretanto, a qualidade da matéria-prima lipídica interfere diretamente na eficácia desses catalisadores.

\title{
5 Synthesis of Biodiesel from Waste Grease Using Factorial Design
}

\begin{abstract}
The aim of this work was to produce biodiesel via enzymatic route, using waste oil as substrate and the factorial design as analysis tool. The factorial design was employed to evaluate the transesterification reaction parameters, regarding the molar ratio oil: ethanol $(1: 3 ; 1: 4.7 ; 1: 9 ; 1: 13.3$ to $1: 15)$ and temperature $\left(30,34,45,56\right.$ and $\left.60^{\circ} \mathrm{C}\right)$. The reaction was conducted in a shaker, using $20 \mathrm{~g}$ of the reaction medium and $2 \mathrm{~g}$ of the immobilized lipase derivative, for $15 \mathrm{~h}$. The different assays were assessed by gas chromatography (verification of ethyl esters content) and viscometer, and showed the production of $67.9 \%$ of ethyl esters for the molar ratio of oil: ethanol of 1: 4.7 and temperature $34^{\circ} \mathrm{C}$ and a viscosity of $3.82 \mathrm{cP}$ for the molar ratio of oil: ethanol of 1: 3 and temperature of $45^{\circ} \mathrm{C}$, these being the best results, indicating that the variable which significantly interfered in the yield of the reaction was the temperature.
\end{abstract}

Keywords: Waste oil; Factorial design; Biodiesel.

\section{Referências}

ARRUDA BOTELHO, C. A. V. de. Viabilidade Técnica e Aspectos Ambientais do Biodiesel Etílico de Óleos Residuais de Fritura. 2012. Dissertação (Programa de Pós-Graduação em Energia) - EP / FEA / IEE / IF da Universidade de São Paulo, São Paulo, 2012

BOX, G. E. P.; HUNTER, W. G.; WUNTER, J. S. Statistics for experimenters: An Introduction to Designs, Data analysis and Model Building. New York:Wiley, 1978.

BRASIL. Agência Nacional de Petróleo, Gás Natural e Biocombustíveis. Resolução $n^{\circ} 14$ de 11 de maio de 2012. Especificação do Biodiesel contida no Regulamento Técnico ANP n 4/2012. Diário Oficial da União, Brasília, DF, seção 1, 18 maio. 2012.
BRASIL. Agência Nacional da Vigilância Sanitária - ANVISA. Resolução n $^{\circ} \mathbf{4 8 2}$ de 23 de setembro de 1999. Aprova o Regulamento Técnico para Fixação de Identidade e Qualidade de Óleos e Gorduras Vegetais. Diário Oficial da União, Brasília, DF, Poder Executivo, 13 outubro. 1999.

BRASIL. Ministério da Agricultura, Pecuária e Abastecimento. Instrução Normativa $n^{\circ} .49$, de 22 de dezembro de 2006. Regulamento Técnico de Identidade e Qualidade dos Óleos Vegetais Refinados; a Amostragem; os Procedimentos Complementares; e o Roteiro de Classificação de Óleos Vegetais Refinados. Diário Oficial da União, Brasília, DF, seção 1, 26 dez. 2006.

BRASIL, 2014. Resolução n $\mathbf{4 5}$, de 25 de agosto de 2014 da Agência Nacional do Petróleo, Gás Natural e Biocombustíveis (ANP), 2014.

CASTRO, H. F. de; MENDES, A. A.; SANTOS, J. C. dos; AGUIAR, C. L. de. Modificação de óleos e 


\section{REA - Revista de estudos ambientais (Online) v.17, n. 2, p.51-59, jul./dez. 2015}

Gorduras por Biotransformação. Química Nova, São Paulo, v. 27, n. 1, p. 146-156, Jan/Feb. 2004.

HA, S.H.; LAN, M.N.; LEE, S.H.; HWANG, S.M.; $\mathrm{KOO}, \mathrm{Y}$. M. Lipase-catalyzed biodiesel production from soybean oil in ionic liquids. Enzyme and Microbial Technology. USA. v. 41, p. 480-483, 2007.

LEIRAS, A. A cadeia produtiva do biodiesel: uma avaliação econômica para o caso da Bahia. 2006. 156f. Dissertação (Programa de Pós-Graduação em Engenharia Industrial) Pontifícia Universidade Católica do Rio de Janeiro, Rio de Janeiro, 2006.

PINTO, A. C.; GUARIEIRO, L. L. N.; REZENDE, M. J. C.; RIBEIRO, N. M.; TORRES, E. A.; LOPES, W. A.; PEREIRA, P. A. D.; DE ANDRADE, J. B. Biodiesel: An overview. Journal of the Brazilian Chemical Society, v. 16, n. 6B, p. 1313-1330, 2005.

SAWIN, J. L. Mainstreaming renewable energy in the 21st century, Wolrdwatch Paper 169: Worldwatch Institute, p. 7-37, 2004. Disponível em:

<http://books.google.com.br/books?id=RDypMDiC onIC\&printsec=frontcover\&hl=pt-

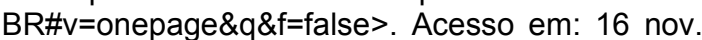
2012,

SCAMILHE, E. de P.; SMITH, L. P.; RÓS, P. M. da; PEREIRA, E.B. Análise de Rendimento dos Óleos de Café e de Soja na Produção de Biodiesel via Rota Enzimática. Resumo. In: ENZITEC 2012 - Xth Brazilian Seminar on Enzyme Technology - 7th -10th of October, 2012, Blumenau, SC, 2012. Disponível em: <http://www.furb.br/enzitec/2012/_app/_FILE_RES UMO_CD/90.pdf>. Acesso em 6 jun. 2014.

SILVA, A. E. Estudo do Processo Enzimático de Produção de Biodiesel a partir de Óleos e Gorduras Residuais de Fritura. 2010. 62f. Dissertação (Programa de Pós-Graduação em Engenharia Química) - Universidade Federal de Alagoas, Maceió, 2010.

SOUZA, M. A. Desemulsificação e Purificação de Resíduos Gordurosos provenientes de esgotos domésticos. 2003. 156f. Dissertação (Programa de Pós-Graduação em Engenharia
Ambiental) - Universidade Regional de Blumenau, Blumenau, 2003.

SOUZA, M. A. Conversão de Resíduos Gordurosos de Frituras com a Produção de Biodiesel por Rota Catalítica Heterogênea. 2010. 178f. Tese (Programa de Pós-Graduação em Engenharia Ambiental) - Universidade Federal de Santa Catarina, Santa Catarina, 2010.

STATSOFT, INC. Programa computacional Statistica 7.0. E.A.U. 2004

TIANWEI, T.; JIKE, L.; KAILI, N.; LI D.; FANG W. Biodiesel production with immobilized lipase: A review. Biotechnology Advances, USA, v. 28, p. 628-634; 2010.

URIOSTE, D.; CASTRO, M. B. A.; BIAGGIO, F. C.; DE CASTRO, H. F. Síntese de padrões cromatográficos e estabelecimento de método para dosagem da composição de ésteres de ácidos graxos presentes no biodiesel a partir do óleo de babaçu. Química Nova, v. 31, n. 2, p. 407-412, 2008

VASCONCELOS, L. G. de; Produção e Biodiesel em Meio Ácido induzido por Microondas $(2,45 \mathrm{GHz})$ em reator de escala piloto. 2011. 173f. Dissertação (Programa de PósGraduação em Engenharia Química) Universidade Federal de Santa Catarina, Florianópolis, 2011

VILLENEUVE, P.; MUDERHWA, J. M.; GRAILLE, J.; HAAS M.J. Customizing lipases for biocatalysis: A survey of chemical, physical and molecular biological approaches. Journal of Molecular Catalysis B: Enzymatic, v. 9, n. 4-6, p. 113-148, 2000.

WANG, Y., WU, H., ZONG, M.H. Improvement of biodiesel production by lipozyme TL IM-catalyzed methanolysis using response surface methodology and acyl migration enhancer. Bioresource Technology. v. 99, p. 7232-7237, 2008.

7 Agradecimentos: A CAPES pelo apoio financeiro, a UNIFAL-MG, a UFSCar pelas análises cromatográficas, a EEL/USP pelas análises de viscosidade e ao Prof. Dr. Adriano Aguiar Mendes pela colaboração no trabalho. 